\title{
Monetary policy in steering the EONIA and POLONIA rates in the Eurosystem and Poland: a comparative analysis
}

\author{
Piotr Fiszeder ${ }^{1}$. Ilona Pietryka ${ }^{2}$
}

Received: 7 January 2015 / Accepted: 10 April 2017 / Published online: 6 July 2017

C The Author(s) 2017. This article is an open access publication

\begin{abstract}
The effectiveness of the monetary policies of the European Central Bank (ECB) and the Narodowy Bank Polski (NBP) is compared directly in terms of influencing the spread between the interbank overnight rate and the main rates of the central banks during periods of different economic conditions, i.e. the global financial crisis of 2008, the European sovereign debt crisis and the period of relative stability. Three categories of determinants of the Euro Overnight Index Average/Polish Overnight Index Average (EONIA/POLONIA) spreads are considered: (1) monetary policy instruments such as open market operations, standing facilities and minimum reserve requirements; (2) measures of liquidity conditions; and (3) market expectations and risk measures. Applying the ARFIMA-GARCH models, we show that the statistical and economic properties of the EONIA and POLONIA spreads are quite different. The EONIA spread has a long memory while the POLONIA spread is characterized by a short memory. This difference is important from the viewpoint of a stabilizing monetary policy. The impact of shocks on the future levels of the spread was stronger for the POLONIA spread, but it was short-lived in comparison with the EONIA spread. Most of the analysed variables significantly influenced the spreads
\end{abstract}

Electronic supplementary material The online version of this article (doi:10.1007/s00181-017-1285-7) contains supplementary material, which is available to authorized users.

$\triangle$ Piotr Fiszeder

piotr.fiszeder@umk.pl

Ilona Pietryka

ilonapietryka@umk.pl

1 Department of Econometrics and Statistics, Faculty of Economics Sciences and Management, Nicolaus Copernicus University in Torun, ul. Gagarina 13a, 87-100 Torun, Poland

2 Department of Economics, Faculty of Economics Sciences and Management, Nicolaus Copernicus University in Torun, ul. Gagarina 13a, 87-100 Torun, Poland 
during the financial crisis, while the biggest differences in the impact of determinants between the EONIA and POLONIA spreads occurred during the period of relative stability. Substantial differences also exist between the volatilities of both spreads.

Keywords Monetary policy · Money market · EONIA and POLONIA spreads · ARFIMA-GARCH model

JEL Classification E43 $\cdot$ E52 $\cdot$ E58 $\cdot$ C22

\section{Introduction}

Since 1990, over 30 central banks, mostly representing developing economies, have followed and adopted the direct inflation targeting (DIT) strategy. The implementation of the DIT as an approach to monetary policy was accompanied by the dissemination of two schools of economic theory in the last decade of the twentieth century: the New Keynesian school and the New Classical school. The DIT makes price stability its primary goal and, in most cases, it reduces the role of formal intermediate targets, such as the exchange rate or money growth (Grostal et al. 2015). The DIT strategy is usually implemented using the operational target, which is an economic variable that the central bank can control, to a great extent, on a daily basis through the use of its monetary policy instruments. Currently, there is a consensus among central banks that the short-term (overnight) nominal interest rate of the interbank market is the appropriate operational target (Bindseil 2004).

The monetary policies of the ECB and the NBP, which have implemented the DIT strategy, are analysed in this study. The ECB's actions are focused on stabilizing the interbank EONIA ${ }^{1}$ rate, and the NBP controls the POLONIA rate. ${ }^{2}$ The desired levels of these rates are reached through the appropriate management of banking sector liquidity by using monetary policy instruments: open market operations, standing facilities, and reserve requirements.

Before the financial crisis, the DIT strategy was implemented without major changes in the size of the central bank's balance sheet, which was primarily driven by autonomous factors (the so-called conventional monetary policy). When the zero lower bound on the policy rate was reached, the conventional policy had lost its strength and unconventional measures were introduced by major central banks (Pattipeilohy et al. 2013). The central banks started influencing broader financial conditions more directly by using quantitative easing, qualitative easing, the balance sheet policy, credit

\footnotetext{
1 The EONIA is a weighted average of all overnight lending transactions between most active credit institutions in the euro area's money market. The ECB formally admits that it steers the short-term interbank interest rates, publishing information regarding the level of the minimum bid rate. However, the properties of the spread between the EONIA rate and the key monetary policy rate suggest that the ECB aims mainly at steering the EONIA rate (Borio and Nelson 2008).

2 The POLONIA is the average overnight rate weighted with the values of transactions on the unsecured interbank deposit market among most active credit institutions in the Polish money market. Starting in 2008, the NBP's official operating target is the POLONIA. The change in the official policy goal from stabilizing the WIBOR SW to stabilizing the POLONIA rate was adjusted according to tendencies in the term structure of the money market (NBP 2012a).
} 
easing, and changes in communication policy. Monetary policy played a key role in the stabilization of the global economy during the financial and sovereign debt crises.

Recent empirical studies are largely based on the euro area market. From the point of view of future Polish membership in the euro area, it is worthwhile and interesting to compare the monetary policies of the ECB and NBP. Over the past few years, Poland has implemented a number of solutions concerning its institutional and operational frameworks to bring them closer to the targets of the Eurosystem. Additionally, these actions are focused on encouraging the development of the money market and the effective implementation of an independent monetary policy. Poland and other countries in Central and Eastern Europe underwent a similar path of economic and political transformation. Compared to other countries, Poland differs in the size of its economy (the highest GDP), its level of economic development, its exchange rate regime, and its degree of integration with the euro area. The comparison is also interesting because the liquidity positions that prevail in the developed banking sector in the Eurosystem and in the developing Polish banking sector are significantly different. The liquidity shortage in the Eurosystem improves the effective use of the interest rate channel of the monetary policy transmission.

This study offers two main contributions. First, it is the first comparison of monetary policies aimed at stabilizing the interbank market rate conducted in a country that is obliged to adopt the euro and simultaneously in the Eurosystem. To our knowledge, there is only one study — that of Beirne et al. (2013) — in which the determinants of the spread between the overnight market interest rate and the main central bank's rate have been analysed simultaneously for two different central banks, i.e. for the ECB and the Bank of England. However, in that study only risk factors and interest rate expectations were examined. Due to different econometric models, different explanatory variables, and different periods, a direct comparison between various studies in the literature is not possible.

The second contribution of this study is to show that the statistical and economic properties of the EONIA and POLONIA spreads are quite different. After controlling for explanatory variables, the EONIA spread still has a long memory. This feature is not present in the POLONIA spread, where only short-term relations are detected. This difference is important from the viewpoint of a stabilizing monetary policy. The impact of shocks on future levels of the spread was stronger for the POLONIA spread, but it was short-lived in comparison with the EONIA spread. This finding was made possible by the application of the ARFIMA-GARCH model with explanatory variables in the mean equation. Kliber et al. (2015) found a long memory in the POLONIA spread for only one out of seven periods. The persistence of the spread was also analysed by Panigirtzoglou et al. (2000) for Germany, Italy, and the UK; by Hassler and Nautz (2008) for the Eurosystem; and by Kliber and Płuciennik (2011) for Poland. They applied, respectively, a simple reduced-form model in parallel with the GARCH model, the ARFIMA model, and tests of long memory. These studies are quite different from the approach adopted in this study because the determinants of the spread were not taken into account in these analyses. According to this research, substantial differences also exist between the volatilities and determinants of the EONIA and POLONIA spreads.

Another feature that makes this study interesting is its comparison of the influences of different monetary policy instruments and measures of liquidity conditions, market 
expectations, and the risk to the spread during periods of disparate economic conditions, i.e. the global financial crisis of 2008, the European sovereign debt crisis, and the period of relative stability.

The remainder of this study is structured as follows. Section 2 presents a brief literature survey. Section 3 very briefly introduces models applied in the study, namely the ARFIMA and GARCH models. Section 4 presents determinants of spreads, the specification of periods and the preliminary results. In Sect. 5, the EONIA/POLONIA spreads are modelled with the ARFIMA-GARCH models. In Sect. 6, we present the interpretation of results, and Sect. 7 summarizes.

\section{Literature review}

The assessment of the effectiveness of the stabilization policy of central banks using econometric methods is a relatively new problem in the literature. Very different approaches and models have been applied in the studies. Research on determinants of the spread between the selected interbank rate and the central bank's main rate can be divided into two groups, namely studies of non-crisis and of financial crisis periods. It is obvious that the monetary policy of central banks will be quite different in both periods. Examples of such studies of tranquil periods in the Eurosystem are the studies of Würtz (2003), Nautz and Offermanns (2008) and Linzert and Schmidt (2010). Würtz (2003) applied the nonlinear model (the transformed logistic function), which takes into account the fact that the spread is capped by the corridor set by standing facilities. Additionally, the GARCH component model, which describes the conditional heteroscedasticity of the spread, was used in that study. Nautz and Offermanns (2008) applied a different approach because they did not analyse the difference between the interbank rate and the central bank's main rate but instead used the error correction model in parallel with the EGARCH model to describe the relation between those two series. The study by Linzert and Schmidt (2010) was based on the linear regression model.

Examples of studies of the financial crisis periods of the Eurosystem are the studies of Abbassi and Nautz (2012), Beirne (2012), Beirne et al. (2013), and Soares and Rodrigues (2013). In studies of the crisis, it is quite clear that more attention was paid to factors related to risk. Abbassi and Nautz (2012) used the error correction model, whereas Beirne (2012) analysed two kinds of models, namely the linear regression model and the vector autoregressive model. Beirne et al. (2013) applied the regression model in parallel with the stochastic volatility model, not only for the Eurosystem but also for the UK. Soares and Rodrigues (2013) applied the linear regression model in parallel with the EGARCH model using two regimes for low and high volatility.

In the following studies, the influence of the NBP on the POLONIA rate was analysed: Kliber and Płuciennik (2011), Ho and Lu (2012) and Kliber et al. (2015). In the first two studies, the linear regression model was applied in parallel with the component GARCH and EGARCH models in the first and second studies, respectively. Kliber et al. (2015) used the ARFIMA model with explanatory variables in parallel with the stochastic volatility model. The time-varying conditional volatility of the spread was found only for three out of seven periods, but it was probably caused by the very short periods applied. 


\section{Econometric methods}

The comparative analysis of the EONIA and POLONIA spreads was performed on the basis of the ARFIMA-GARCH models with explanatory variables. These models are described very briefly as follows.

The ARFIMA model (see Granger and Joyeux 1980), which is a generalization of the ARIMA model, can capture long-term dependencies between observations of series. The $\operatorname{ARFIMA}(p, d, q)$ model can be written as:

$$
\varphi(L)(1-L)^{d}\left(y_{t}-\mu_{t}\right)=\vartheta(L) \varepsilon_{t},
$$

where $\varphi(L)=1-\sum_{j=1}^{p} \varphi_{j} L^{j}, \vartheta(L)=1+\sum_{j=1}^{q} \vartheta_{j} L^{j}, L$ denotes the lag or the backshift operator $\left(L^{s} \varepsilon_{t}=\varepsilon_{t-s}\right), d$ is the fractional integration parameter, which satisfies $-0.5<d<0.5$, and $\varepsilon_{t}$ is white noise. The binomial expansion of $(1-L)^{d}$ is defined as follows:

$$
(1-L)^{d}=\sum_{k=0}^{\infty}\left(\begin{array}{l}
d \\
k
\end{array}\right)(-L)^{k} .
$$

The process described by formula (1) is stationary when $d<0.5$ and all roots of the equation $\varphi(L)=0$ lie outside the unit circle. When $d \in(0 ; 0.5)$, the ARFIMA process is called a long memory process. When $d=0$, the process in (1) is the $\operatorname{ARMA}(p, q)$ process and is a short memory process. When $d \in(-0.5 ; 0)$, the process has an intermediate memory.

The explanatory variables $X_{1}, X_{2}, \ldots, X_{k}$ of the dependent variable $y_{t}$ can be additionally included in Eq. (1):

$$
\mu_{t}=\gamma_{0}+\gamma_{1} X_{1 t}+\gamma_{2} X_{2 t}+\cdots+\gamma_{k} X_{k t} .
$$

The $\operatorname{GARCH}(P, Q)$ model proposed by Bollerslev (1986) is defined as:

$$
\begin{gathered}
\varepsilon_{t}=z_{t} \sqrt{h_{t}}, \\
h_{t}=\alpha_{0}+\sum_{i=1}^{Q} \alpha_{i} \varepsilon_{t-i}^{2}+\sum_{j=1}^{P} \beta_{j} h_{t-j},
\end{gathered}
$$

where $z_{t}$ is a series of independent, identically distributed random disturbances and $z_{t} \sim N(0,1)$.

Nelson and Cao (1992) give necessary and sufficient conditions to ensure the non-negativity of the conditional variance. For the simple $\operatorname{GARCH}(1,1)$ model, the positivity of $h_{t}$ requires that $\alpha_{0}>0, \alpha_{1} \geq 0$ and $\beta_{1} \geq 0$. The process in (5) is covariance stationary, if and only if $\alpha_{1}+\alpha_{2}+\cdots+\alpha_{Q}+\beta_{1}+\beta_{2}+\cdots+\beta_{P}<1$.

The ARFIMA model describes the mean equation, while the GARCH model describes the variance equation. The GARCH model is frequently used to forecast the volatility of financial time series (see, for example, Fiszeder and Perczak 2016). 


\section{Determinants of spreads, specification of periods, and preliminary results}

The direction (liquidity absorbing or providing) and the scale of instruments used by central banks both depend on the liquidity position of the banking sector in the Eurosystem and in Poland, which is measured on the basis of the consolidated liquidity balance sheet. The liquidity position of the banking sector is affected by autonomous factors, which are beyond the direct control of the central bank. ${ }^{3}$ Their level is adjusted with monetary policy instruments. ${ }^{4}$ Both items are balanced by the level of the banks' current accounts in the central bank. Liquidity positions in the Eurosystem and Poland, and the degree of their correction by the central banks for the periods analysed in this study are presented in Fig. 1. The precise description of the periods is given as follows.

There is a liquidity shortage in the Eurosystem, the scale of which is determined by the level of net autonomous factors corrected by net monetary policy instruments. Accumulated excess funds (above the required reserve) are held on the banks' current accounts in the ECB. This situation does not change the fact that there is a liquidity shortage within the banking sector in the Eurosystem. The level of net autonomous factors indicates the liquidity surplus in the Polish banking sector, which is not completely absorbed by net monetary policy instruments. Excess funds in banks' current accounts in the Eurosystem and the liquidity surplus in Poland make the EONIA and POLONIA rates run below the central bank's main rates (Figs. 2, 3). In the case of the Eurosystem, this situation has persisted since the beginning of the financial crisis. Before the crisis, the EONIA spread was usually positive.

The differences between the liquidity position of the interbank market in the Eurosystem and Poland, the NBP's and the ECB's monetary frameworks, and other institutional features of monetary policy were taken into account when choosing the determinants of the EONIA/POLONIA spreads. The selected factors, which have their counterparts in the Eurosystem and Poland, were divided into three categories. The detailed explanation of variables and their theoretical impact on the EONIA/POLONIA spreads (cf. Linzert and Schmidt 2010; Ho and Lu 2012) is provided in Table 1. The first category includes central bank activities, which are given by monetary policy instruments such as open market operations (MRO, LTRO, FTD, MAIN, REPO, and $B I L L S)$, standing facilities $(S F)$, and minimum reserve requirements $(M R)$. The second category contains a variable describing the liquidity conditions of the banking sector, i.e. excess reserves $(E R)$. The third category includes variables affecting the market's

\footnotetext{
3 The net autonomous factors in the Eurosystem and Poland are calculated as follows: net foreign assets minus banknotes in circulation minus central government deposits minus other liquidity-absorbing factors.

4 The ECB's net monetary policy instruments are calculated according to the following formula: the main refinancing operations plus the longer-term refinancing operation plus the marginal lending facility plus other liquidity-providing operations minus the deposit facility minus other liquidity-absorbing operations. The NBP's net monetary policy instruments are calculated as follows: the marginal lending facility plus other liquidity-providing operations minus the deposit facility minus main and fine-tuning open market operations.
} 


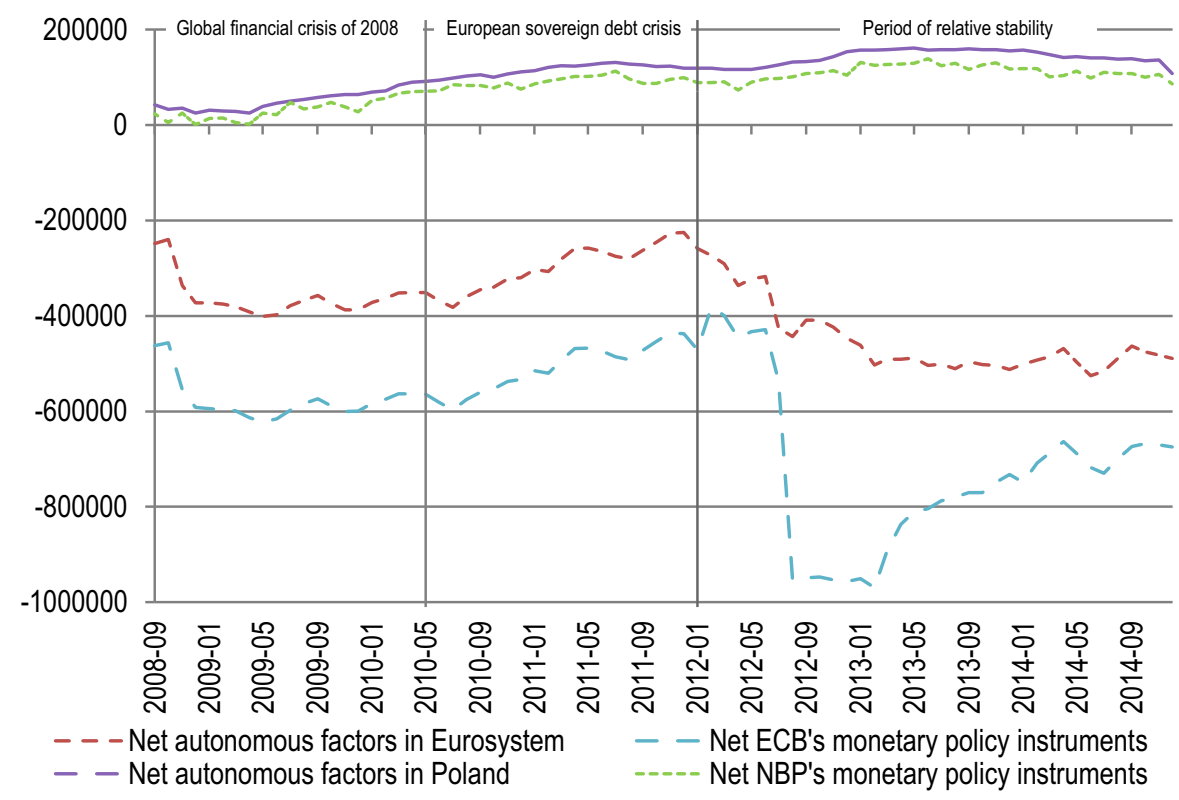

Fig. 1 Liquidity shortage in the Eurosystem and the liquidity surplus in Poland and their degrees of absorbance/provision by central banks (in millions of EUR/PLN)

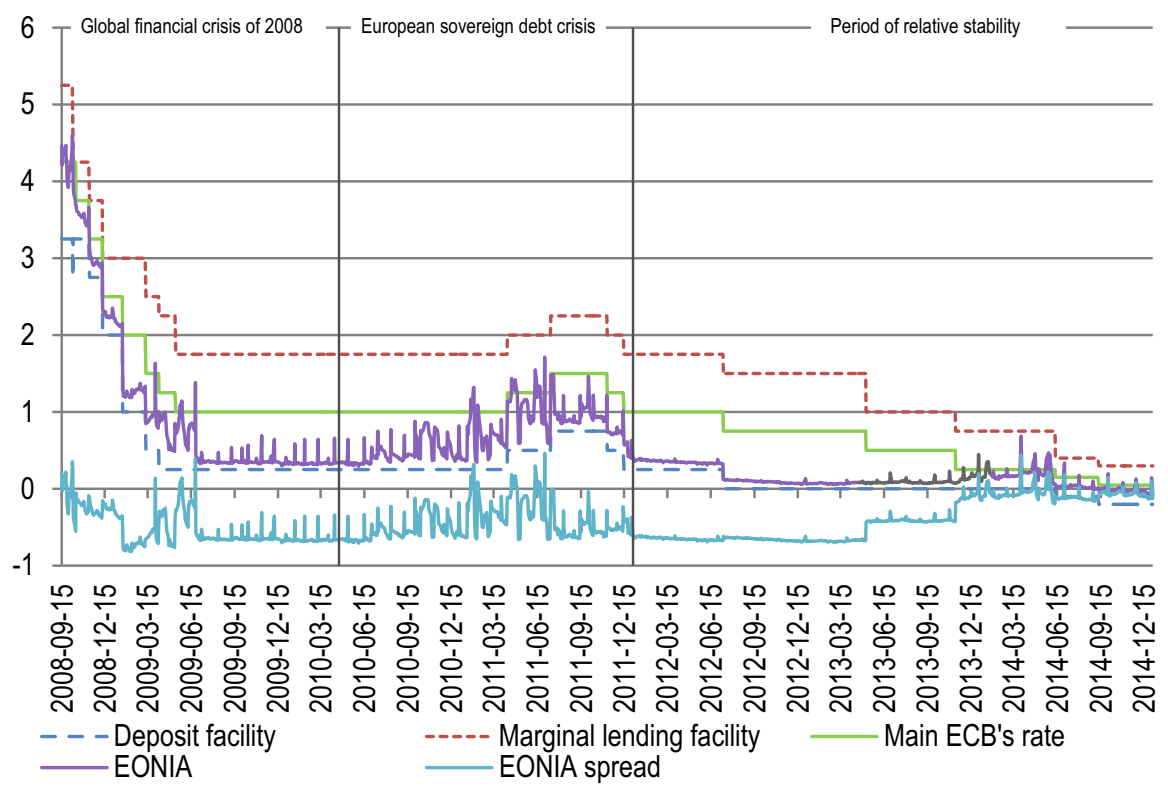

Fig. 2 EONIA rate in the ECB's policy rates corridor and the EONIA spread (in \%)

expectations regarding changes in short-term rates $(O I S-M R)$ and the risk associated with short-term rates (VAROIS). The third category also includes risk variables such as credit risk (EURIBOR/WIBOR-OIS) and the sovereign CDS premia (CDS). 


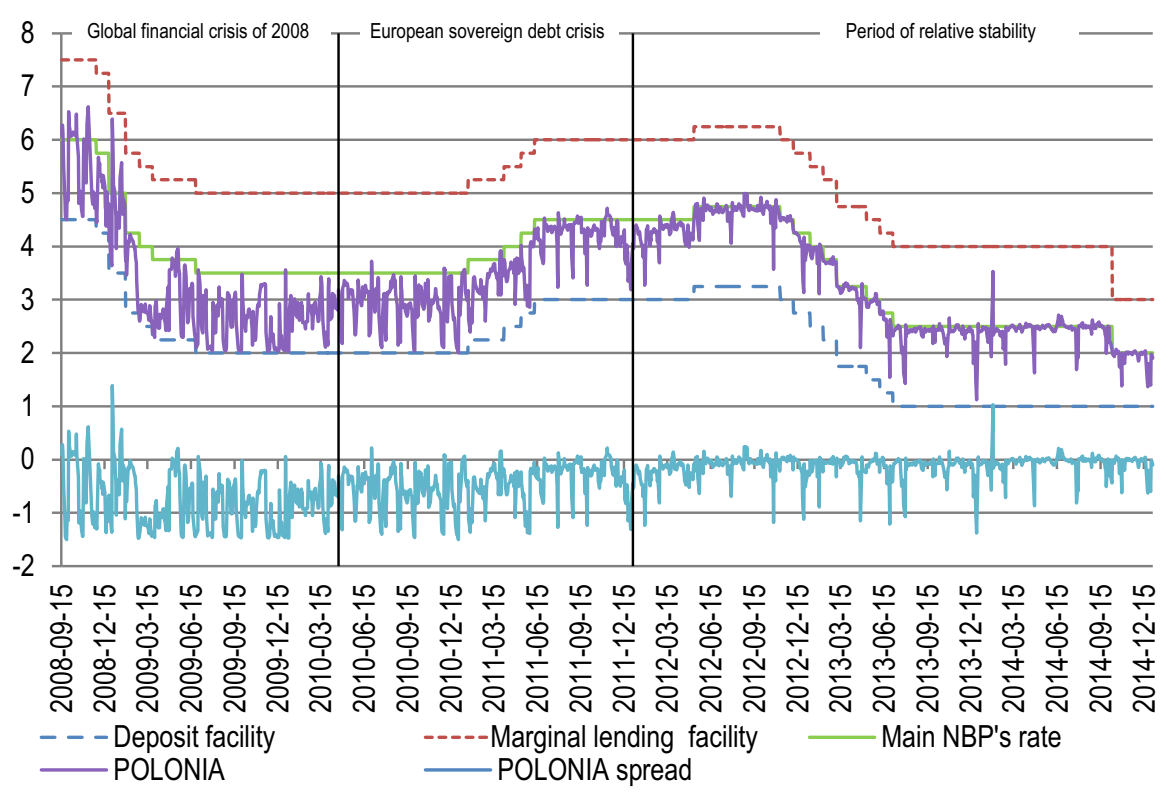

Fig. 3 POLONIA rate in the NBP's policy rates corridor and the POLONIA spread (in \%)

A negative impact on the EONIA/POLONIA spreads is expected for the following variables: $M R O, L T R O, R E P O, E R$, and SF. The increase in these factors is associated with the growth of the liquidity supply for the first four variables and with the decrease in the liquidity demand for the last variable, and it subsequently causes a drop in interbank rates. A positive impact on the EONIA/POLONIA spreads is expected for the variables MAIN, FTD, BILLS, MR and for market expectations and risk measures. The rise of these factors is associated with the decrease in the liquidity supply for the first three features and with the increase in the liquidity demand for the variable $M R$, and consequently it causes the increase in interbank rates. The variable OIS-MR represents expectations of the future dynamics of short rates at the 1-week horizon. The factor VAROIS signifies the risk concerning short rates at the 1-week horizon. The variable EURIBOR/WIBOR-OIS describes the credit risk in the interbank market, and the variable CDS represents the risk premium of euro area countries and Polish insolvency. The increase in expectations and the risk perceived by investors can contribute to offering higher rates on the interbank market. Therefore, a positive impact on the EONIA/POLONIA spreads is expected.

The study was performed for three periods characterized by disparate economic conditions and different types of monetary policies, i.e. the global financial crisis of 2008, the European sovereign debt crisis, and the period of relative stability. These periods are as follows:

- the global financial crisis of 2008-from 15 September 2008 to 22 April 2010;

- the European sovereign debt crisis-from 23 April 2010 to 30 December 2011;

- the period of relative stability_from 1 January 2012 to 31 December 2014. 


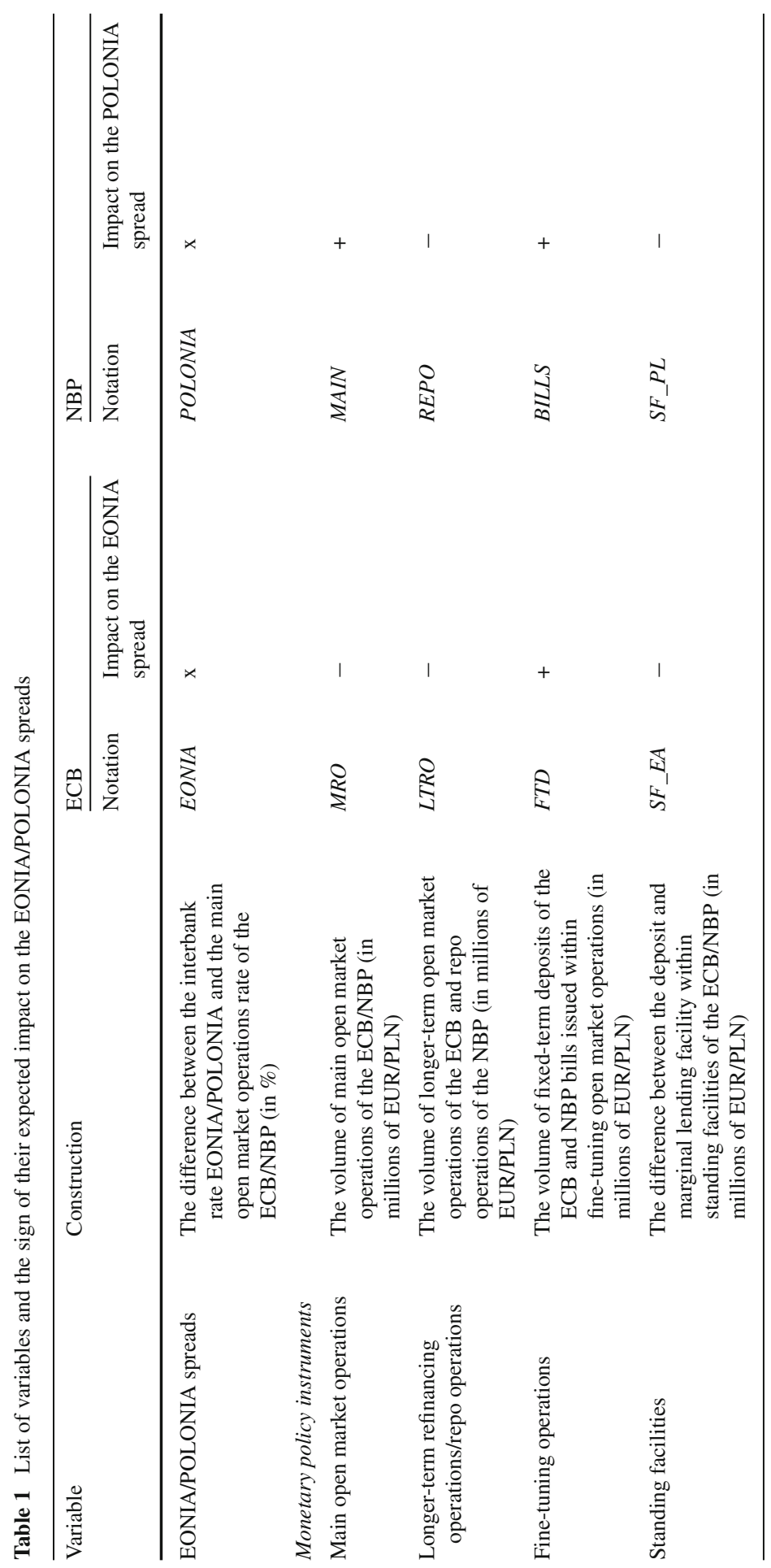




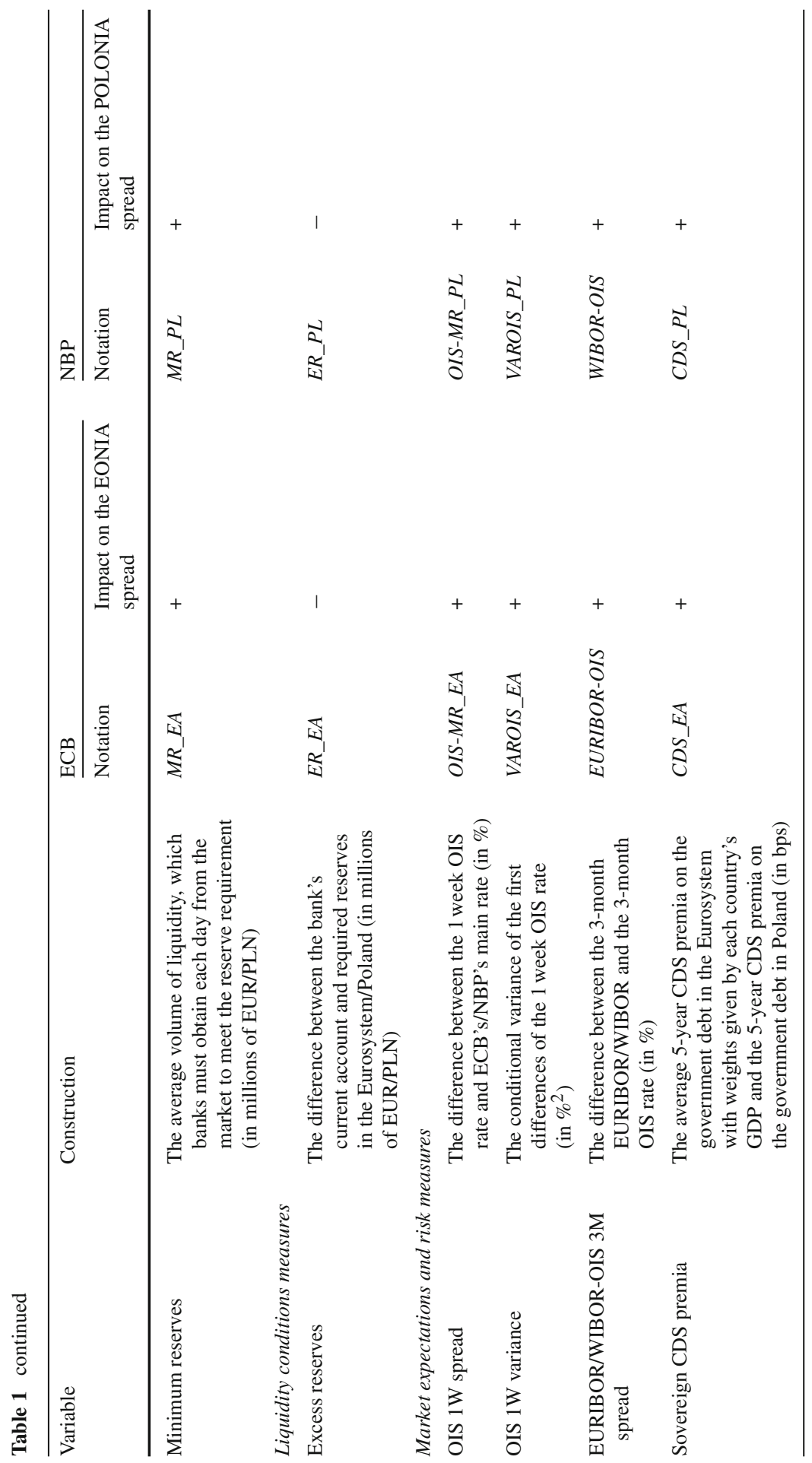


Table 2 Mean values and standard deviations of the EONIA and POLONIA spreads

\begin{tabular}{|c|c|c|c|c|c|c|}
\hline \multirow[t]{2}{*}{ Spread } & \multicolumn{2}{|c|}{ Global financial crisis of 2008} & \multicolumn{2}{|c|}{ European sovereign debt crisis } & \multicolumn{2}{|c|}{ Period of relative stability } \\
\hline & Mean & SD & Mean & SD & Mean & SD \\
\hline EONIA & -0.5107 & 0.2377 & -0.4373 & 0.2210 & -0.3947 & $0.0491^{\mathrm{a}}$ \\
\hline POLONIA & -0.7562 & 0.5271 & -0.4541 & 0.3790 & -0.1125 & 0.2064 \\
\hline
\end{tabular}

a Two dummy variables connected with the reduction in the ECB's interest rates on 8 May 2013 and on 13 November 2013 were included in the calculation of the standard deviation

The day on which the bankruptcy of Lehman Brothers was announced-i.e. when the worst phase of the financial crisis occurred in the USA and the turbulence spread to the European financial markets-was assumed in this study to be the beginning of the global financial crisis. Almost 2 years later, the euro area began to struggle with the debt crisis. Due to the difficult budgetary situation, the Greek government requested official financial assistance from the EU and the IMF on 23 April 2010. This date was adopted as the start of the second period. According to González-Páramo (2009), a member of the ECB Executive Board, after April 2010 the sovereign debt crisis phase can be distinguished in the ECB's monetary policy. Efforts to overcome the crisis in Europe have produced a number of measures such as the European Financial Stability Facility (EFSF), the European Financial Stabilization Mechanism (EFSM, May 2010), and the Euro Plus Pact (March 2011). The ECB established the securities markets programme (SMP) and the covered bond purchase programme (CBPP) to support better functioning of the monetary policy transmission mechanism. Greece, Ireland, Portugal, Cyprus, and Spain received financial assistance from the European rescue funds, obliging them to implement budgetary reforms. At the end of 2011, the ECB decided on additional enhanced credit support measures to support bank lending and liquidity in the euro area money market. The first operation occurred on 21 December 2011, and January 2012 was treated as the beginning of the period of relative stability. The main transmission channel of this non-standard monetary policy measure works through the mitigation of liquidity and funding risks in the euro area banking system, which ultimately contributes to relaxing bank lending standards and supports the financing of the economy at large (Darracq-Paries and De Santis 2015). The largest share went to Italian and Spanish banks, which in turn used it, to some extent, to expand their portfolios of national sovereigns, thus earning the large spreads between ECB financing and distressed sovereigns (Micossi 2015). The extraction of the three above-mentioned periods is substantiated not only from the economic point of view but also from the statistical one. Statistical measures of the spreads, such as mean values or standard deviations (presented in Table 2), are significantly different in the three periods, which was confirmed by the bootstrap tests (presented in Table A1 in Online Appendix A).

Daily data were analysed, and all data were obtained from ECB and NBP statistics and the Thomson Reuters Datastream. At the beginning, $\mathrm{Ng}$ and Perron and Zivot and Andrews unit root tests were applied for all variables. The results are presented in Tables B1-B6 in Online Appendix B. Both the EONIA and POLONIA spreads were integrated of order zero in all periods. The stationarity of spreads indi- 
cates that both the ECB and NBP did not lose the ability to control the overnight rate.

The values of the mean of both spreads in all three periods were negative (see Figs. 2, 3). This means that the EONIA and POLONIA rates were usually below the central bank's main rate. This indicates the liquidity surplus of the Polish banking sector and is a sign that the Eurosystem's interbank market is strongly segmented. Banks from countries particularly affected by the debt and confidence crisis, having no access to ordinary financing, were forced to acquire liquidity through relatively more expensive loans refinanced from the ECB, the cost of which was close to the ECB's main rate. However, strong and reliable banks (usually from Northern Europe) acquired their financing at a lower cost, marked by the persistently low EONIA (Antolin-Diaz 2013). Because in Poland the POLONIA rate was closer to the NBP's main rate, the refinancing cost from the central bank was similar to the cost from the interbank market. The lowest levels of the spreads and the highest standard deviations were observed during the period of the global financial crisis (see Figs. 2, 3). The estimate of the mean of the EONIA spread was higher, and the level of its volatility was slightly lower, during the period of the European sovereign debt crisis. These differences, compared with the period of the global financial crisis, were significantly higher for the POLONIA spread. The European sovereign debt crisis had an impact on the heterogeneity of monetary policy transmission across the euro area and posed particular challenges for the single monetary policy (Cour-Thimann and Winkler 2012).

At first glance, the EONIA spread is unstable in the third period (see Fig. 2). However, there were two upward shifts connected with the reduction in the ECB's interest rates. On 8 May 2013, the ECB narrowed the width of the interest rate corridor around the main rate from 150 to $100 \mathrm{bps}$. Later, on 13 November 2013 the interest rate corridor was narrowed further to $75 \mathrm{bps}$ and it became asymmetric. When these shifts in interest rates are taken into account in calculations, it turns out that the spread is very stable. Thus, dummy variables were applied in both unit root tests and also in the estimation of the standard deviation, and parameters of the ARFIMA-GARCH models (these are presented in Sect. 5).

The highest level of the spreads and the lowest level of their standard deviations occurred during the period of relative stability. The POLONIA rate returned to the NBP's main rate, while a little later-i.e. at the end of November 2013-the EONIA rate returned to the ECB's main rate. The level of volatility of the spreads was always higher for the POLONIA rate. Despite the still unstable macroeconomic situation in the euro area, the central bank's monetary policy created relatively stable conditions in the banking sector, and the volatility of the EONIA/POLONIA spreads declined in 2012. In mid-2013, the ECB introduced a type of forward guidance, a communication policy instrument, to clarify the path of key interest rates in the near future, reducing uncertainty and interest rate volatility (Illing and Siemsen 2015; Filardo and Hofmann 2014). The use of the permanent rules of the banking sector's liquidity management and the stabilization of the interbank market limited the willingness of banks to borrow funds at rates other than the central bank's main rate. This allowed the central bank to restore confidence in the interbank market. 


\section{Modelling the EONIA and POLONIA spreads with the ARFIMA-GARCH models}

Time series of spreads between the interbank rate and the central bank's main rate have quite specific properties, such as autocorrelation, long memory, ARCH effects, and leptokurtosis of distributions. This implies that modelling such data is not an easy task and that simple econometric methods are not always methodologically correct. In this study, the ARFIMA-GARCH model, with explanatory variables in the mean equation, was applied. Such an approach permits the analysis of the determinants of the spread, but simultaneously describes the aforementioned properties of the data.

In accordance with the results of the unit root tests (see Sect. 4), first differences were calculated for all exogenous variables, which were integrated of order one. The choice of lag lengths $p$ and $q$ in the ARFIMA model, lag lengths $P$ and $Q$ in the GARCH model, and the lag length of explanatory variables in all cases was based on the minimization of the Bayesian information criterion. The model with one lag for explanatory variables was adopted for both spreads and all three periods. Because the degree of leptokurtosis induced by the time-varying conditional variance did not capture all of the leptokurtosis present in the spreads data, the parameters of the models were estimated by the quasi-maximum likelihood method. The results of the estimation are shown in Tables 3, 4 and 5 for each period separately.

The main difference between the EONIA and POLONIA spreads during the global financial crisis of 2008 refers to the memory of the processes (see Table 3). The estimate of the fractional integration parameter for the EONIA spread is relatively high, but it is still less than 0.5 . This indicates the existence of the long memory of the spread. However, the fractional integration parameter was not significantly different from zero for the POLONIA spread, ${ }^{5}$ which is why the AR model was applied instead of the ARFIMA model. However, short memory is observed, and the estimates of parameters for lagged spread are relatively high. This indicates that both the ECB and NBP maintained the ability to control the interbank rates during the global financial crisis; however, the nature of the spreads was different. The EONIA spread depended strongly on more distant lags; however, the POLONIA spread relied heavily on the first two lags.

There were no significant differences in the properties of volatility between the EONIA and POLONIA spreads. Conditional variances of both spreads were described by the GARCH $(1,1)$ models.

All the analysed determinants significantly influenced the EONIA spread during the global financial crisis (the 0.05 level of significance was assumed in this study). However, the following variables affected the POLONIA spread: $R E P O, S F \_P L, M R \_P L, E R \_P L, O I S-M R \_P L, V A R O I S \_P L, C D S \_P L$. Except for four variables_-MRO, FTD, VAROIS_EA, and VAROIS_PL-the sign of the influence was consistent with expectations (see Table 1). The opposite impact of these four determinants was probably a consequence of the very turbulent crisis period. In some cases, such as $O I S-M R \_E A$, the contemporaneous relation is different from the lagged one.

5 Due to space limitations, the results are not presented, but they are available from the authors upon request. 


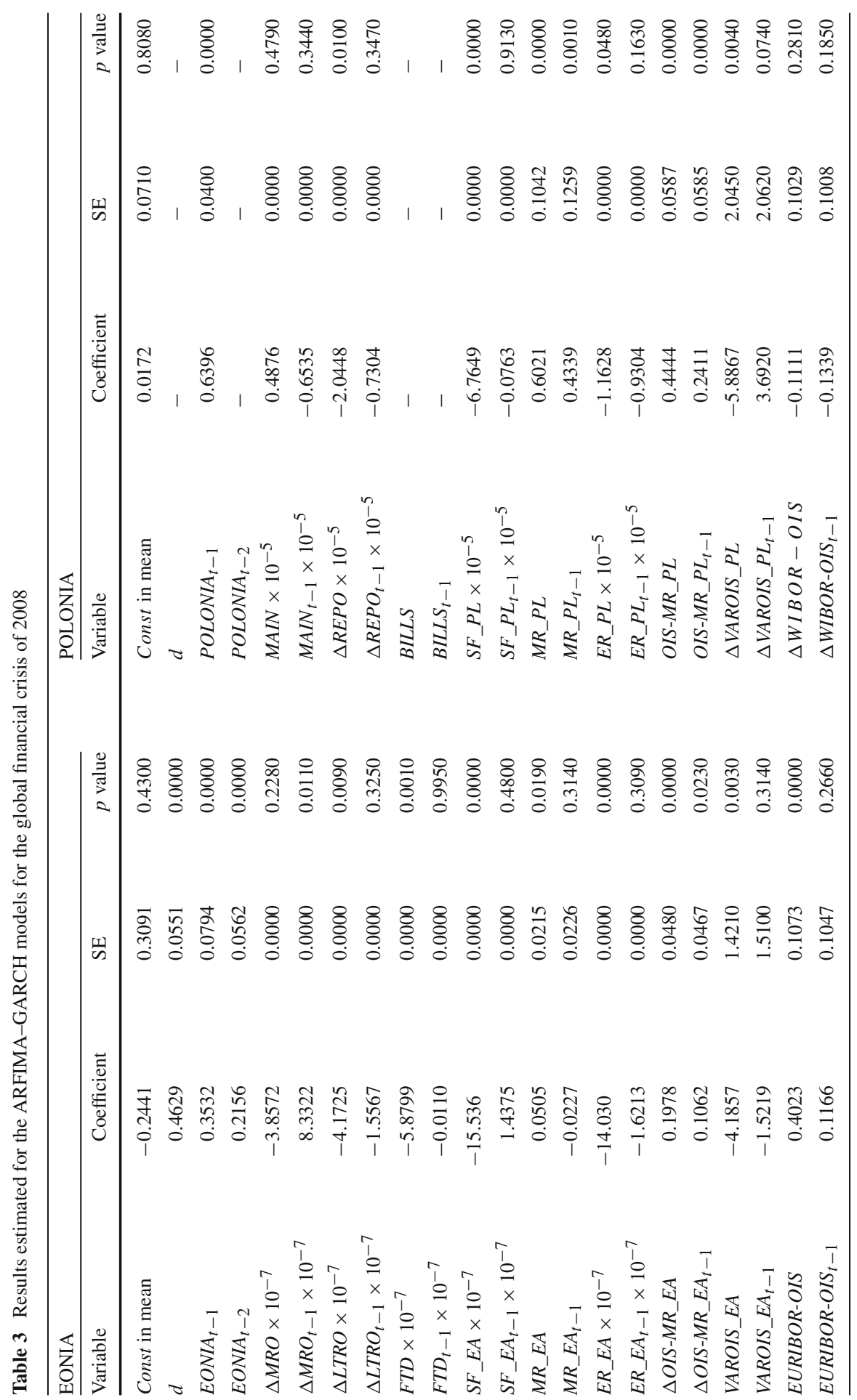




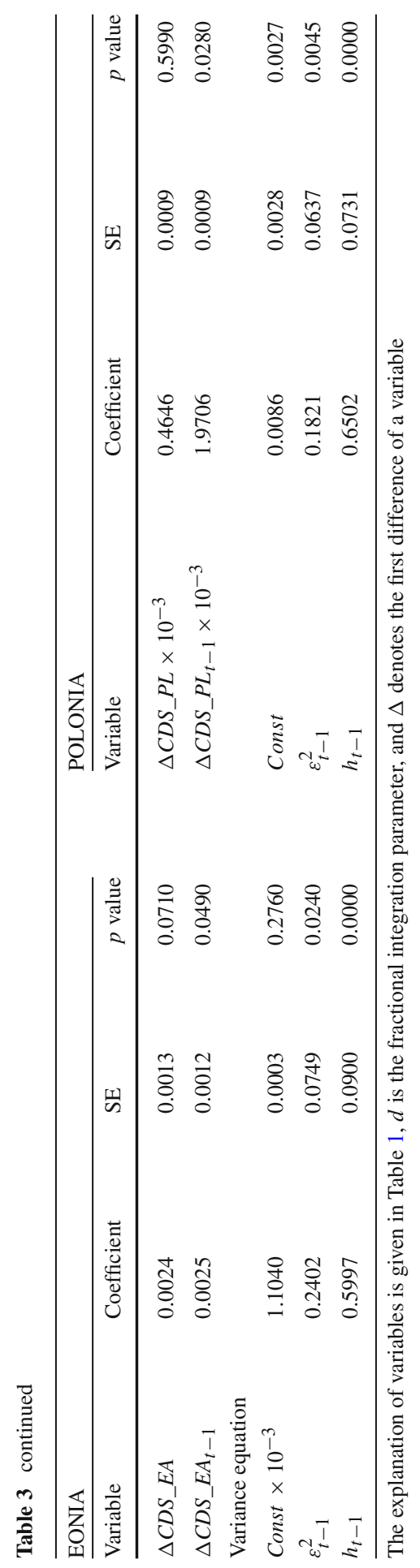




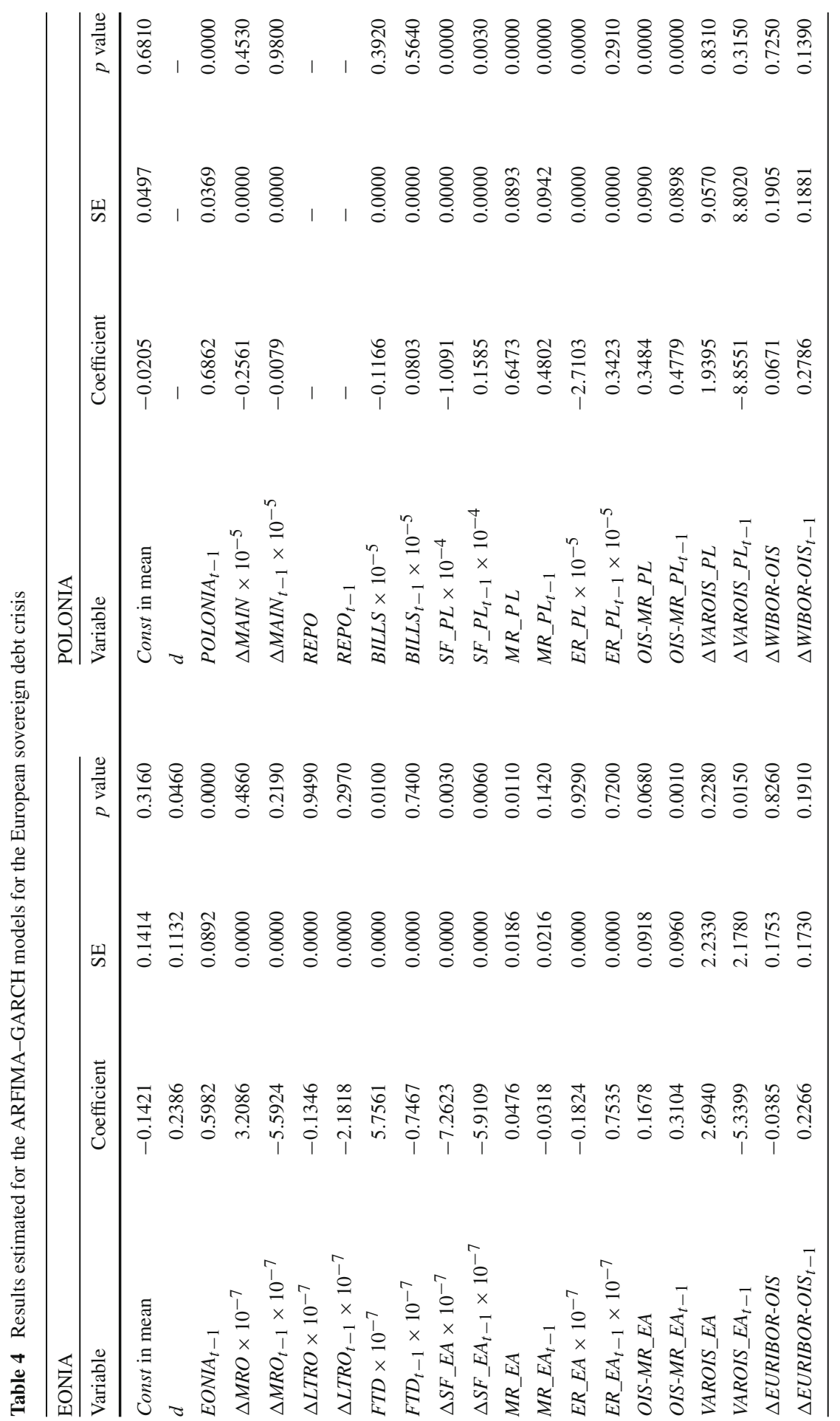




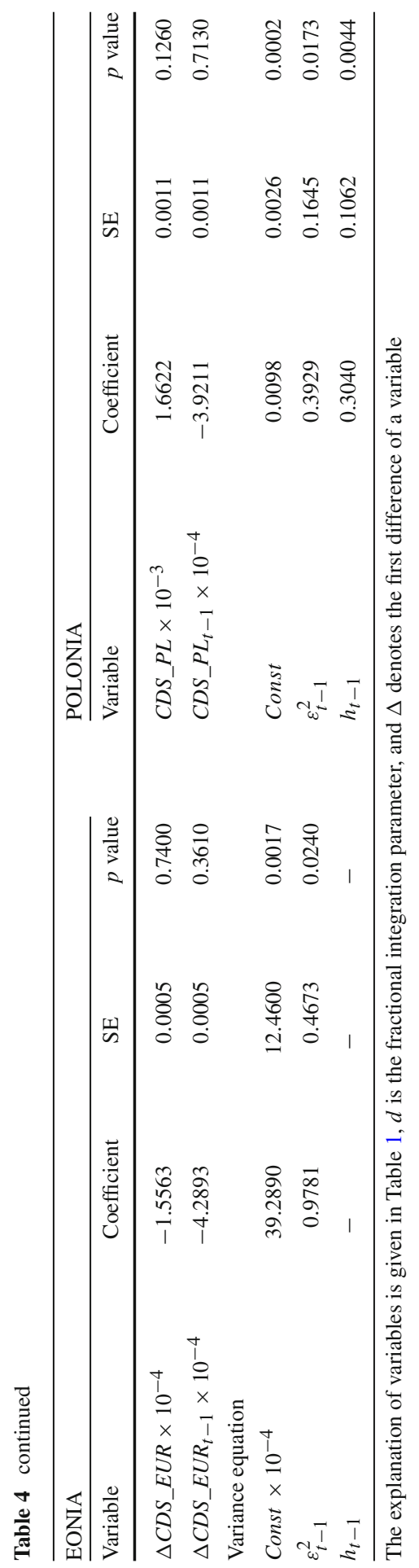




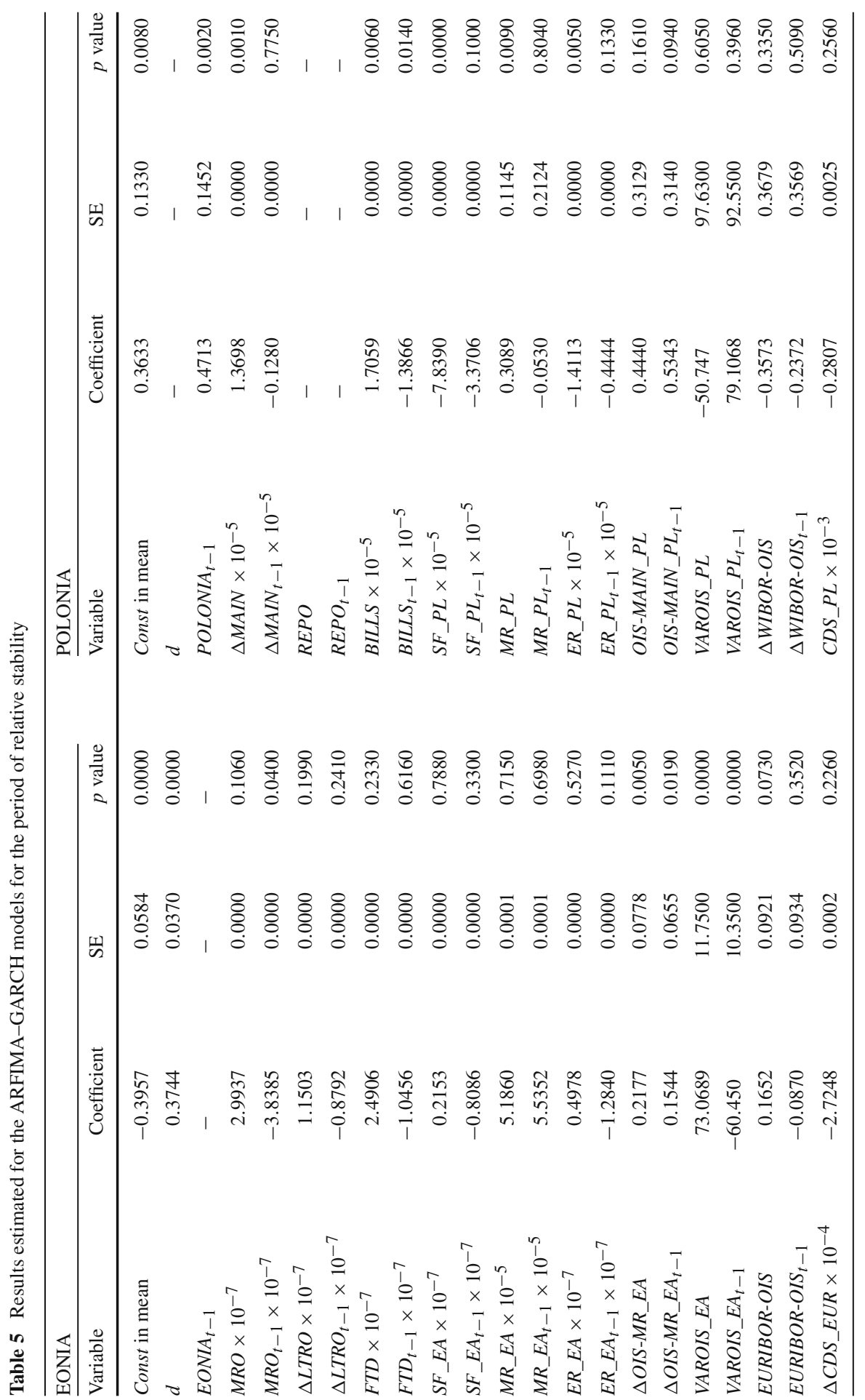




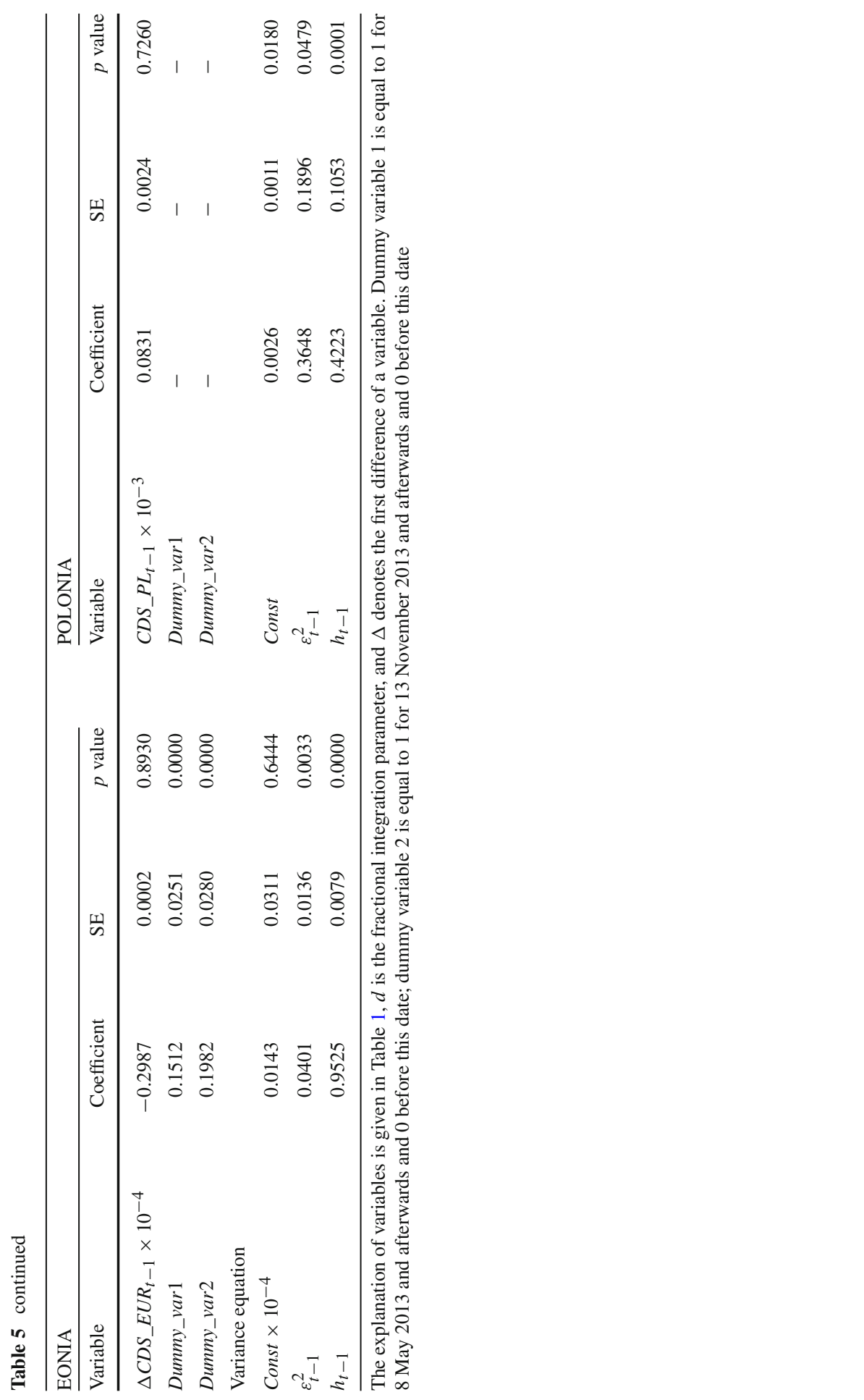


The joint effect of such variables depends on the stronger relation. The significance of the influence of many determinants is similar for both the EONIA and POLONIA spreads; however, for two variables, i.e. MRO/MAIN and EURIBOR/WIBOR-OIS, the results are different. The BILLS variable was not considered in the model for the period of the global financial crisis because the NBP conducted its fine-tuning operation (issuing NBP bills of shorter maturity than 7 days) only a few times. These operations have been used more frequently since December 2010.

The EONIA spread again exhibited the long memory property during the European sovereign debt crisis (see Table 4). However, the estimate of the fractional integration parameter was lower compared with the period of the global financial crisis, which indicates the higher degree of controllability of the EONIA rate by the ECB. The POLONIA spread again exhibited only the short memory property. The substantial difference between the EONIA and POLONIA spreads also existed in volatility. The conditional variance of the EONIA spread was described by the $\mathrm{ARCH}(1)$ model, while the GARCH $(1,1)$ model was necessary for the POLONIA spread. This indicates that the variability of the EONIA spread depended only on the volatility the day before, while the second-moment dependences of the POLONIA spread were more long term. However, the impact of shocks on future volatility was much stronger for the EONIA spread and was probably caused by the rapid reactions of the participants in the Eurosystem's interbank market during the European sovereign debt crisis.

The following determinants significantly influenced the EONIA spread during the period of the European sovereign debt crisis: $F T D, S F \_E A, M R \_E A$, OIS-MR_EA, VAROIS_EA. However, the following variables affected the POLONIA spread: $S F \_P L, M R \_P L, E R \_P L, O I S-M R \_P L$. Therefore, the number of determinants was lower for both spreads compared with the period of the financial crisis. For the lagged VAROIS_EA and lagged $S F \_P L$, the sign of the influence was inconsistent with what was expected (see Table 1). For three variables-i.e. FTD/BILLS, $E R$ and VAROIS - the results of the influence were different between the EONIA and POLONIA spreads. The variable REPO was not considered in the model for the period of the European sovereign debt crisis. The NBP resigned from conducting liquidity by providing repo operations because of high liquidity in the banking sector in the fourth quarter of 2010.

The EONIA spread exhibited the long memory property during the third period, i.e. the period of relative stability (see Table 5). However, the POLONIA spread exhibited only the short memory property. This was in contrast to the EONIA spread, where the lagged variables were not significant. This suggests that in all three considered periods the NBP had more control over the interbank rate during the long-term period; however, it was more difficult to control the rate during the short-term period. The substantial differences between the EONIA and POLONIA spreads also existed for volatility. Although the conditional variances of both spreads were described by the GARCH(1,1) models, dissimilarities were present in the estimates of the parameters. The impact of shocks on future volatility was much stronger for the EONIA spread (the sum of estimates of the parameters $\alpha_{1}$ and $\beta_{1}$ in Eq. (5) was significantly higher for the EONIA spread).

The following determinants significantly influenced the EONIA spread during the period of relative stability: $M R O, O I S-M R \_E A$, and VAROIS_EA. Additionally, two 
dummy variables were applied to describe the narrowing of the interest rate corridor by the ECB (see the explanation in Sect. 4). However, the following variables affected the POLONIA spread: $M A I N, B I L L S, S F \_P L, M R \_P L, E R \_P L$. For all determinants except $M R O / M A I N$, the significance of the influence is different between the EONIA and POLONIA spreads. This indicates that differences in the monetary policies of the ECB and NBP are more visible during the stability period.

To evaluate the quality of the models, several statistical tests were performed. The results of the Ljung-Box test for the presence of autocorrelation and the Engle test for the presence of the ARCH effect are provided in Table $\mathrm{C} 1$ in Online Appendix C. There is no autocorrelation or conditional heteroscedasticity in the residuals of the models. The results of the Durbin-Wu-Hausman test for endogeneity are presented in Table D1 in Online Appendix D. The explanatory variables are exogenous. All the performed tests confirm a good quality of the presented models. Additionally, the joint influence of the variables of the Eurosystem on the POLONIA spread was verified and was not significant according to the F-test for omitted variables (see Tables E1-E3 and F1 in Online Appendices E and F).

\section{The interpretation of the results for the determinants of the EONIA/POLONIA spreads}

The variables from the first category of determinants, i.e. monetary policy instruments, often had an impact on the EONIA/POLONIA spreads which was statistically significant and consistent with what was expected. Among them, the variables $S F$ and $M R$ most often influenced the spreads. The variable $S F$ had a negative influence on the EONIA/POLONIA spreads level. The significant impact of this variable in all periods (except $S F_{-} E A$ in the period of the relative stability) can be explained by changes in the liquidity management system of commercial banks. They held excess funds (above the level of reserve requirements) mainly as the deposit facilities of central banks (Fahr et al. 2013). The marginal lending facility has been used infrequently. Second, the crisis caused instability in the interbank market, which was reflected in the increased counterparty risk due to insolvency, the decline in the turnover on shortterm, unsecured interbank deposits, and the introduction of credit limits (Rodríguez and Carrasco 2016). The lack of influence of the variable $S F \_E A$ during the period of relative stability was probably caused by the reduction in the ECB's deposit rate to zero on 11 July 2012. The zero bound was technically reached, and after 11 June 2014, the ECB's deposit rate was negative. This reduced the amount of money in the deposit facility and increased the amount of excess reserves in banks' current accounts, hence the decline in the ECB's net instruments in mid-2012 (see Fig. 1).

The variable $M R$ had a positive influence on the EONIA/POLONIA spreads, consistent with what was expected. The purpose of this variable was to describe the periodic pattern of spreads connected with the obligation of commercial banks to maintain their required reserve level. The significant impact of this variable in all periods (except $M R \_E A$ in the period of relative stability) is connected with the phenomenon of frontloading, which was reflected in an earlier fulfilment of the banks' reserve requirement (Lenza et al. 2010). Frontloading also causes fluctuations in the EONIA and POLONIA 
rates on the last days of the maintenance period. The lack of influence of the variable $M R \_E A$ during the period of relative stability was probably caused by a reduction in the ECB's reserve ratio from 2 to $1 \%$ on 18 January 2012 (Al-Eyd and Berkmen 2013). This greatly reduced the required reserve stock.

The variable FTD had a negative impact on the EONIA spread during the period of the global financial crisis. However, this result was caused by the existence of the negative correlation between the determinants FTD and $E R$, and it should be interpreted only in relation to these three variables. The relationship was not, however, strong enough to have a negative impact on the properties of estimators of parameters in the model. Instead, as expected, the variable FTD had a positive influence on the spread in the period of the European sovereign debt crisis. Moreover, this variable did not play a significant role in the period of relative stability. This is plausible because, in order not to make the securities markets programme (SMP) an outright quantitative tool, the ECB decided to carry out its weekly draining auction under fixed-term deposits in the years 2010-2014 (Borio and Disyatat 2010). Additionally, the ECB conducted finetuning operations to counter the liquidity imbalance on the last day of the maintenance period. The number of sterilization auctions failed, and in December 2011, the ECB suspended fine-tuning operations on the last day of the maintenance period. The ECB's liquidity-absorbing monetary policy instruments have declined since the beginning of 2012 (see Fig. 1).

The variable BILLS had a positive influence on the POLONIA spread during the period of relative stability (the joint effect of the contemporaneous and lagged relation of BILLS was positive). On 11 December 2010, the NBP implemented irregular, shortterm fine-tuning operations during the reserve maintenance period. Additionally, it introduced overnight fine-tuning operations on the last day of the maintenance period on 29 June 2011 (Kliber et al. 2015). The frontloading requirement caused the fall in the level and the rise in the volatility of the POLONIA spread. The aforementioned measures implemented by the NBP were effective in decreasing these negative results.

The variable $M R O$ had an impact on the EONIA spread during the period of the global financial crisis (positive) and the period of relative stability (negative). However, the variable MAIN positively influenced the POLONIA spread during the period of relative stability. Moreover, as expected, the variable LTRO had a negative influence on the spread during the period of the global financial crisis. The increase in the variables $M R O$ and $L T R O$ is associated with the growth of the liquidity supply and subsequently causes a fall in interbank rates; hence, the negative impact on the EONIA spread is expected. However, the rise in the variable MAIN is associated with the decrease in the liquidity supply and consequently causes the increase in interbank rates; hence, the positive impact on the POLONIA spread is expected. The positive influence of the variable $M R O$ during the global financial crisis is the only unexpected result that we are unable to explain. The main refinancing operations $M R O$ and $M A I N$ were intended to be the main source of the liquidity supply in the Eurosystem and of liquidity demand in Poland (see Fig. 1). The ECB set their sizes based on forecasts of the liquidity demand. During the financial crisis, it got harder to estimate the need for liquidity (banks reduced the demand for central banks' open market operations, which resulted in a lower demand for liquidity and caused the phenomenon known as underbidding). This gave commercial banks access to unlimited liquidity from the central bank (Fahr 
et al. 2013). ${ }^{6}$ Since 2008, the importance of long-term refinancing operations (LTRO) has grown (in the period 2008-2014 they provided approximately $80 \%$ of all liquidity supply). The ECB changed the loan conditions by expanding the list of assets eligible for collateral and by the extension of the maturities of LTROs (from 3 to 6 months in November 2008 and to 12 months in June 2009) (Rodríguez and Carrasco 2016). All these measures contributed to enormous excess liquidity in banks' accounts in the Eurosystem. Moreover, the ECB extended the maturities of LTROs to 36 months in December 2011. Open market operations, both in the Eurosystem and Poland, were used by central banks, mainly to balance the liquidity position of banks that lacked access to refinancing on the interbank market due to the confidence crisis. Central banks have only a limited ability to control the EONIA/POLONIA rates through open market operations, mainly due to difficulties in forecasting the liquidity position in the banking sector (especially autonomous factors such as banknotes in circulation).

The influence of the variable $R E P O$ was negative on the POLONIA spread during the period of the global financial crisis. Repo operations were used by the NBP only in years 2008-2010 to provide the market with additional liquidity. Due to excess liquidity in the Polish banking sector, banks were no longer interested in participating in repo operations.

The variable $E R$, which belongs to the second category of determinants, i.e. measures of liquidity conditions, in most cases had a negative impact on the EONIA/POLONIA spreads, which was consistent with expectations. Interestingly, the variable $E R \_E A$ did not play a significant role during the period of the European sovereign debt crisis (when the amount of excess liquidity was drastically increased) or during the period of relative stability (when excess liquidity had been on a declining trend as parts of LTRO were being repaid), which resulted in a decreasing trend in the size of excess funds in banks' current accounts. The influence of excess liquidity on the EONIA spread was muted because the central banks lowered interest rates and the ECB also narrowed the interest rate corridor several times (ECB 2009-2015; NBP 2009-2015). ${ }^{7}$ The corridor was asymmetric in the Eurosystem in the period from 13 November 2013 to 10 June 2014 (see Fig. 2). A narrower corridor allows the central bank to steer the interbank rate more efficiently and it reduces the volatility of the rate. However, such a corridor lowers the interbank turnover and requires more frequent intervention by the central bank in money markets (Bindseil and Jablecki 2011).

The variables from the third category of determinants, associated with expectations and risk, also influenced the EONIA/POLONIA spreads. The variable OIS-MR had

\footnotetext{
6 This is the so-called passive liquidity management conducted by the NBP from 2 January 2009 to 13 February 2009 and by the ECB from 15 October 2008 to this day. The intent of these actions was to reassure banks that in the case of a liquidity shock, they could balance their liquidity position through the central bank at a known rate for a known period and as much as they needed.

7 During the period of the global financial crisis, the ECB cut the main rate from 4.25 to $1.00 \%$ and narrowed the interest rate corridor from 200 to $150 \mathrm{bps}$, while the NBP cut the main rate from 6.00 to $3.50 \%$ and left the interest rate corridor unchanged at $300 \mathrm{bps}$. In the first half of the European sovereign debt crisis period, the ECB increased the main rate from 1.00 to $1.50 \%$, but in the second half of this period the ECB cut the main rate to $1.00 \%$ while the NBP increased the main rate from 3.50 to $4.50 \%$. Both central banks left the interest rate corridor unchanged. In the period of relative stability, the ECB cut the main rate from 1.00 to $0.05 \%$ and narrowed the interest rate corridor from 150 to $50 \mathrm{bps}$, while the NBP cut the main rate from 4.50 to $2.00 \%$ and narrowed the interest rate corridor from 300 to $200 \mathrm{bps}$.
} 
a positive impact on the EONIA/POLONIA spreads in all periods except for the period of relative stability in Poland. This result is in line with the theory of rational expectations.

The variable VAROIS_EA had a statistically significant influence on the EONIA spread during all periods. However, the variable VAROIS_PL influenced the POLONIA spread in the period of the global financial crisis. Only in the period of relative stability, the impact confirms the presumptions. This may mean that the risk concerning the future path of short-term rates during the confidence crisis caused banks to choose less risky activities, such as the deposit facility on the deposit rate, which is below the central bank's main rate. The variables EURIBOR-OIS and CDS had a positive impact on the EONIA/POLONIA spreads only during the period of the global financial crisis. The core euro area countries made further decisions to ensure the solvency of the peripheral countries, which had problems with their public finances. This is why the credit risk and the insolvency risk of the euro area and Poland were less noticeable during and after the period of the European sovereign debt crisis.

\section{Conclusion}

The overnight interbank rates-i.e. EONIA and POLONIA - are viewed as operational targets of the ECB and NBP. The desired levels of these rates (which should be consistent with the final inflation target) are reached through the appropriate management of banking sector liquidity by using monetary policy instruments: open market operations, standing facilities, and reserve requirements. Since the outbreak of the financial crisis, the ECB and NBP have also implemented many unconventional measures. Monetary policy played a key role in stabilizing the global economy during the financial and sovereign debt crises.

In this study, we directly compared the ECB's and NBP's monetary policy effectiveness in terms of influencing the spread between the interbank overnight rate and the main rates of the central banks during periods of disparate economic conditions, i.e. the global financial crisis of 2008, the European sovereign debt crisis, and the period of relative stability. The ARFIMA-GARCH models with explanatory variables in the mean equation were applied for both spreads.

We showed that the statistical and economic properties of the EONIA and POLONIA spreads are quite different. First, after controlling for three groups of determinants, i.e. monetary policy instruments, liquidity conditions measures, and market expectations and risk measures, the EONIA spread still exhibited the long memory property in all three periods. This feature is not present in the POLONIA spread, where only short-term relations were detected. Both the ECB and NBP maintained the ability to control the interbank rates, but changes in the spread in the Eurosystem had a more long-term character than in Poland. This difference is important from the viewpoint of a stabilizing monetary policy. The impact of shocks on the future levels of the spread was stronger for the POLONIA spread but it was short-lived in comparison with the EONIA spread. Second, except for the period of the global financial crisis, the substantial differences between the EONIA and POLONIA spreads also exist in the parametrizations of conditional variances; specifically, the impact of shocks on 
future volatility was much stronger for the EONIA spread. Third, most of the variables significantly influenced the spreads during the financial crisis, while the biggest differences in the impact of determinants between the EONIA and POLONIA spreads occurred during the period of relative stability.

Open Access This article is distributed under the terms of the Creative Commons Attribution 4.0 International License (http://creativecommons.org/licenses/by/4.0/), which permits unrestricted use, distribution, and reproduction in any medium, provided you give appropriate credit to the original author(s) and the source, provide a link to the Creative Commons license, and indicate if changes were made.

\section{References}

Abbassi P, Nautz D (2012) Monetary transmission right from the start: on the information content of the Eurosystem's main refinancing operations. N Am J Econ Financ 23:54-69. doi:10.1016/j.najef.2011. 11.002

Al-Eyd AJ, Berkmen P (2013) Fragmentation and monetary policy in the euro area. IMF Working Papers, vol 13, pp 1-31. doi:10.5089/9781484328750.001

Antolin-Diaz J (2013) Understanding the ECB's monetary policy. Fulcrum Research Notes, pp 1-8

Beirne J (2012) The EONIA spread before and during the crisis of 2007-2009: the role of liquidity and credit risk. J Int Money Financ 31:534-551. doi:10.1016/j.jimonfin.2011.10.005

Beirne J, Caporale GM, Spagnolo N (2013) Liquidity risk, credit risk and the overnight interest rate spread: a stochastic volatility modelling approach. Manch Sch 81:925-940. doi:10.1111/j.1467-9957.2012. 02330.x

Bindseil U (2004) Monetary policy implementation. theory, past, present. Oxford University Press, New York

Bindseil U, Jablecki J (2011) The optimal width of the central bank standing facilities corridor and bank's day-to-day liquidity management. ECB Working Paper, vol 1350, pp 1-35

Bollerslev T (1986) Generalized autoregressive conditional heteroscedasticity. J Econ 31:307-327. doi:10. 1016/0304-4076(86)90063-1

Borio C, Disyatat P (2010) Unconventional monetary policies: an appraisal. Manch Sch 78:53-89. doi:10. 1111/j.1467-9957.2010.02199.x

Borio C, Nelson W (2008) Monetary operations and the financial turmoil. BIS Q Rev 3:31-46

Cour-Thimann P, Winkler B (2012) The ECB's non-standard monetary policy measures: the role of institutional factors and financial structure. Oxf Rev Econ Policy 28:765-803. doi:10.1093/oxrep/grs038

Darracq-Paries M, De Santis R (2015) A non-standard monetary policy shock: the ECB's 3-year LTROs and the shift in credit supply. J Int Money Financ 54:1-34. doi:10.1016/j.jimonfin.2015.02.011

ECB (2009-2015) Annual reports 2008-2014. https://www.ecb.europa.eu. Accessed 2 Jan 2015

Fahr S, Motto R, Rostagno M, Smets F, Tristani O (2013) A Monetary policy strategy in good and bad times: lessons from the recent past. Econ Policy 28:243-288. doi:10.1111/1468-0327.12008

Filardo A, Hofmann B (2014) Forward guidance at the zero bound. BIS Q Rev 3:37-53

Fiszeder P, Perczak G (2016) Low and high prices can improve volatility forecasts during periods of turmoil. Int J Forecast 32:398-410. doi:10.1016/j.ijforecast.2015.07.003

González-Páramo JM (2009) The conduct of monetary policy-lessons from the crisis and challenges for the coming years. http://www.bis.org/review/r111013c.pdf. Accessed 2 Jan 2015

Granger CWJ, Joyeux R (1980) An Introduction to long memory time series models and fractional differencing. J Time Ser Anal 1:15-29. doi:10.1111/j.1467-9892.1980.tb00297.x

Grostal W, Ciżkowicz-Pękała M, Niedźwiedzińska J, Skrzeszewska-Paczek E, Stawasz E, Wesołowski G, Żuk P (2015) Ewolucja strategii celu inflacyjnego w wybranych krajach. https://www.nbp.pl/ publikacje/bci/ewolucja-strategii-celu-inflacyjnego.pdf. Accessed 2 Jan 2015

Hassler U, Nautz D (2008) On the persistence of the EONIA spread. Econ Lett 101:184-187. doi:10.1016/ j.econlet.2008.08.004

Ho G, Lu Y (2012) What drives the POLONIA spread in Poland? IMF Working Paper 12:22-37

Illing G, Siemsen T (2015) Forward guidance at the zero lower bound in a model of price-level targeting. CESifo Econ Stud 61:47-67. doi:10.1093/cesifo/ifv011 
Kliber A, Kliber P, Płuciennik P, Piwnicka M (2015) POLONIA dynamics during the years 2006-2012 and the effectiveness of the monetary policy of the National Bank of Poland. Empirica 43:37-59. doi:10. 1007/s10663-015-9287-1

Kliber A, Płuciennik P (2011) An assessment of monetary policy effectiveness in POLONIA rate stabilization during financial crisis. Bank i Kredyt 42(4):5-30

Lenza M, Pill H, Reichlin L (2010) Monetary policy in exceptional times. Econ Policy 25:295-339. doi:10. 1111/j.1468-0327.2010.00240.x

Linzert T, Schmidt S (2010) What explains the spread between the Euro Overnight Rate and the ECB's policy rate? Int J Financ Econ 16:275-289. doi:10.1002/ijfe.430

Micossi S (2015) The monetary policy of the European Central Bank (2002-2015). CEPS Spec Rep 109

Nautz D, Offermanns CJ (2008) Volatility transmission in the European money market. N Am J Econ Financ 19:23-39. doi:10.1016/j.najef.2007.07.005

NBP (2009-2015) Annual reports 2008-2014. Banking sector liquidity. NBP Monetary policy instruments. http://www.nbp.pl. Accessed 2 Jan 2015

NBP (2012a) System operacyjny polityki pieniężnej Narodowego Banku Polskiego w latach 2008-2012. https://www.nbp.pl/publikacje/sopp/System_operacyjny_polityki_pienieznej_NBP_w_ latach_2008-2012.pdf. Accessed 2 Jan 2015

Nelson DB, Cao CQ (1992) Inequality constraints in the univariate GARCH model. J Bus Econ Stat 10:229235. doi:10.1080/07350015.1992.10509902

Panigirtzoglou N, Proudman J, Spicer J (2000) Persistence and volatility in short-term interest rates. The Bank of England Working Paper, vol 116, pp 2-46. doi:10.2139/ssrn.234696

Pattipeilohy C, van den End JW, Tabbae M, Frost J, de Haan J (2013) Unconventional monetary policy of the ECB during the financial crisis: an assessment and new evidence. De Nederlandsche Bank Working Paper 381:1-45

Rodríguez C, Carrasco C (2016) ECB policy responses between 2007 and 2014: a chronological analysis and an assessment of their effects. Panoeconomicus 63:455-473. doi:10.2298/pan1604455r

Soares C, Rodrigues PMM (2013) Determinants of the EONIA spread and the financial crisis. Manch Sch 81:82-110. doi:10.1111/manc. 12010

Würtz FR (2003) A comprehensive model on the Euro Overnight Rate. European Central Bank Working Papers 207 